\title{
Effects of delayed testing on passive avoidance of conditioned fear stimuli in young rats
}

\author{
RICK RICHARDSON, DEBBIE L. EBNER, and DAVID C. RICCIO \\ Kent State University, Kent, Ohio 44242
}

\begin{abstract}
Deficits in passive avoidance learning in immature animals have been explained in terms of immature response-inhibition mechanisms, the role of age-specific defense responses to conditioned or unconditioned stimuli, or differential levels of fear acquisition. In Experiment 1, shock-elicited UCRs and fear strength were held constant by training all subjects at the same age. Sixteen-day-old rat pups received Pavlovian fear conditioning and were tested 1, 5, or 10 days later for passive avoidance of the conditioned stimuli. To offset retention losses, half of each group received a noncontingent footshock reactivation $24 \mathrm{~h}$ before testing. Passive avoidance latencies increased with delay (age) in reactivated groups. But with an active avoidance (escape from fear) measure (Experiment 2), performance was consistently poor and unrelated to age at testing. These data suggest that maturation of response-inhibition mechanisms may contribute to the ontogeny of passive avoidance performance. More generally, some implications of the distinction between learning and performance for developmental studies are considered.
\end{abstract}

A variety of studies have found that immature organisms perform more poorly than adults in tasks involving the withholding of a response. For example, when rats receive punishment contingent upon crossing from one distinctive compartment into another, passive avoidance performance improves as a function of age (Riccio, Rohrbaugh, \& Hodges, 1968). Similar outcomes have been obtained with other types of punishment tasks and with other species (Blozovski \& Cudennec, 1980; Brunner, 1969; Jensen \& Davis, 1978; Mattingly \& Zolman, 1980; Ray \& Nagy, 1978). Although the empirical phenomenon seems reasonably well established, several different explanations of the effect have been offered. One notion, based on the observation that passive avoidance learning improves over a developmental span in which active avoidance is relatively invariant, is that immature organisms may lack appropriate inhibitory mechanisms (Riccio et al., 1968; Schulenburg, Riccio, \& Stikes, 1971). We suggested that young rats acquired Pavlovian fear conditioning and instrumental responses removing them from these cues (e.g., active avoidance) as readily as adults but were deficient in their ability to withhold responses that brought them into contact with fear stimuli. Although independent evidence of "response-inhibition" deficits was lacking, the parallel between the ontogenetic findings and similar selective disruptions of avoidance in limbic-lesioned rats (McCleary, 1966), along with evidence that cell development in the hippocampus continues until the postweaning period (Altman \& Das, 1965), lent credence to the notion.

This research was supported in part by Grant MH-30223 to the third author. We thank William Jehle and David Zehr for their assistance on various aspects of the study.
More recently, however, a variety of findings have seriously challenged a response-inhibition hypothesis. Smith and Spear (1978) found that a simple environmental manipulation (i.e., the introduction of home-cage shavings during training) substantially improved the passive avoidance learning in 16-day-old pups. Others have extended Bolles' (1970) view that species-specific defense responses interact with task requirements by emphasizing the role of age-specific behaviors in accounting for developmental changes in passive avoidance learning. To the extent that age-specific behaviors elicited by shock or fear are incompatible with passive avoidance requirements (e.g., running rather than freezing), performance will be reduced. In this vein, Bronstein and Hirsch (1976) have shown that freezing to novel stimuli does not emerge until after weaning in the rat, and Collier and Bolles (1980) and Hinderliter and Riccio (Note 1, Note 2) have demonstrated ontogenetic changes in the response to the type of footshock often used in passive avoidance tasks. Stehouwer and Campbell (1980) specifically examined the influence of task requirements by employing a circular chamber in which wall-contacting responses were punished in rat pups ranging from 10 to 15 days of age. Although developmental differences were obtained, Stehouwer and Campbell called attention to the important role played by the changing nature of the response repertoire to shock. Furthermore, 10-day-old pups can learn rapidly in a choice situation involving punishment if an alternative is available (Collier \& Mast, 1979).

An alternative approach to these issues would be to condition fear in rats at an early age but delay the passive avoidance test until the subjects are more mature. In this way, the nature of the UCR elicited and the initial level of fear conditioning are held constant. 


\section{EXPERIMENT 1}

The aim of this experiment was to measure passive avoidance performance 1,5 , or 10 days after fear conditioning in 16-day-old rats. Because the relatively rapid forgetting that occurs in young rats (Campbell \& Spear, 1972) could offset any gains in the subjects' ability to inhibit responding, one-half of each group received a single noncontingent footshock (NCFS) as a memory reactivation (Spear \& Parsons, 1976) 1 day prior to testing.

\section{Method}

Subjects. Sixty 16-day-old naive rats bred in the breeding colony at Kent State University were used as subjects. Subjects were housed in $19 \times 10.5 \times 8$ in. polycarbonate cages. All animals remained in the litter except during experimental sessions. Food and water were available ad lib.

Apparatus. A $38 \times 18 \times 21 \mathrm{~cm}$ black-and-white shuttlebox was used. A $15-\mathrm{W}$ bulb was suspended $30 \mathrm{~cm}$ above the white side. The floor consisted of 4-mm stainless steel grids spaced $1 \mathrm{~cm}$ apart. Only the grids on the black side of the apparatus could be electrified. A guillotine doorway, $8 \times 8 \mathrm{~cm}$, separated the two chambers.

Procedure. All subjects were ear-punched at 15 days of age for identification purposes. Pavlovian differential fear conditioning consisted of four consecutive 5-min sessions. During each of two sessions on the black side of the apparatus, six shocks $(150 \mathrm{~V}, 2 \mathrm{sec})$ were administered on a variable-time schedule. No shocks were presented during the sessions in which the subjects were confined to the white side of the apparatus.

After the appropriate retention interval, strength of passive avoidance responding was measured. The test procedure consisted of placing the rat on the white side facing away from the door (which was in place) and $10 \mathrm{sec}$ later opening the door. Latency to enter into the black side (all four paws) was recorded. If any animal did not cross into the black side in $600 \mathrm{sec}$, the test was terminated and that animal received a latency score of $600 \mathrm{sec}$.

Animals were tested at one of three different retention intervals: 1 day, 5 days, or 10 days. Thus, there were three groups that received Pavlovian conditioning only and were tested at one of three different retention intervals and three additional groups that were also tested at one of the three intervals but received an NCFS $24 \mathrm{~h}$ prior to testing.

\section{Results and Discussion}

Figure 1 displays the mean latencies to enter the previously shocked compartment as a function of the retention interval. An analysis of variance indicated a significant effect of treatment $(F=8.08, p<.006)$, no effect of retention interval $(\mathrm{F}=.13, \mathrm{p}<.8)$, and a marginally significant interaction $(\mathrm{F}=2.75, \mathrm{p}<.07)$. Subsequent $t$ tests indicated that the only significant pairwise comparison was between the two 10-day retention interval groups (NCFS vs. no reactivation; $\mathrm{t}=2.23, \mathrm{p}<.05$, two-tailed).

Despite the fact that all pups were conditioned at 16 days of age, age-related improvements in the ability to withhold responding were found in the reactivation condition. The short latencies of the nonreactivated animals indicated that the increased passive avoidance was not an artifact of a decline in exploratory or motor activity. Thus, these data provide further evidence that noncontingent shock can alleviate infantile amnesia

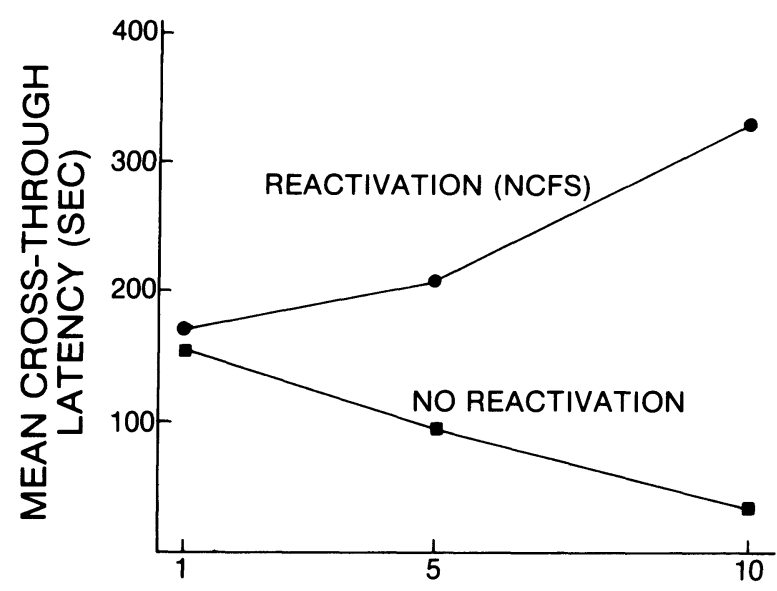

\section{RETENTION INTERVAL (DAYS)}

Figure 1. Mean passive avoidance of conditioned fear cues as a function of delay of testing. All subjects received Pavlovian conditioning at 16 days of age.

(cf. Riccio \& Haroutunian, 1979; Spear \& Parsons, 1976). But of more central interest is the ontogeny of passive avoidance. Explanations based upon developmental differences in shock-elicited UCR, or in acquisition of fear, are not applicable in this paradigm. However, maturation of inhibitory functioning or changes in agespecific responses to fear stimuli could account for the data.

\section{EXPERIMENT 2}

If developmental changes in the response repertoire to fearful cues are responsible for the improvement in passive avoidance performance as a function of age, then their effect on active avoidance should be detrimental. For example, if emergence of freezing responses mediates withholding behaviors, these same characteristics should disrupt performance in a flight task. The design here was identical to that in the preceding experiment, except that testing involved active avoidance, or, more accurately, an escape-from-fear task (McAllister \& McAllister, 1971).

\section{Method}

Subjects. Forty-four rats from the same source and housed identically to the subjects in Experiment 1 served as subjects.

Apparatus. The apparatus used was the same as that used in Experiment 1.

Procedure. All procedures were identical to those in Experiment 1 , with the exception that an escape-from-fear test was used instead of passive avoidance. The fear-escape paradigm, which is generally viewed as a form of active avoidance, consisted of placing the animals on the black (fear) side without shock for 1515 -sec trials. If an escape to the other compartment was not made in $15 \mathrm{sec}$, the animal was removed. A 30 -sec ITI separated each trial.

\section{Results}

Under the conditions employed here, very few "avoidance" responses, defined as leaving the fear 
compartment in less than $15 \mathrm{sec}$, occurred and the groups were indistinguishable. At the 1-day retention interval, only 5 of 22 subjects made more than two avoidances in the first 15 trials; of these, 3 were in the no-reinstatement condition and 2 were in the reinstatement condition. Similarly, after 10 days, only 6 of the 22 subjects made more than two avoidance responses; 5 of these animals were in the no-reinstatement group. At the short retention interval, $7 \%$ was the median proportion of avoidances made by each of the groups; at the 10-day interval, the scores were $13 \%$ and $7 \%$ for the nonreactivated and reactivated groups, respectively.

While these negligible levels of responding may simply indicate that conditioning was too weak to support escape from fear, the results suggest that the age-related changes in passive avoidance performance (Experiment 1) are not due to simple differences in activity or age-specific responses to fear-eliciting stimuli. If high activity in 17-day-old pups contributed to their passive avoidance deficit in Experiment 1, one might have expected the activity level to facilitate performance in the active avoidance test. Although the mirror-image symmetry of Experiments 1 and 2 would have been maintained better by using a single extended escapefrom-fear trial, the repeated 15 -sec trials procedure was chosen to promote active avoidance by disrupting any prolonged freezing behavior.

\section{GENERAL DISCUSSION}

These data are consistent with the notion that passive avoidance learning is mediated in part by a response inhibition mechanism that is poorly developed in preweanling rats. Thus, lack of response inhibition may still be a viable explanation for some developmental deficits in learning about punishment.

The age-related improvement in passive avoidance responding may represent another instance of the widely accepted, but sometimes overlooked (cf. Riccio \& Haroutunian, 1977), distinction between learning and performance. What a young organism acquires, such as fear to environmental or response-linked stimuli, may fail to be expressed in performance until certain other mechanisms have developed more fully. Livesey and Dawson (1977) have drawn similar conclusions based upon the substantial savings found when 26 -day-old rats trained in a discriminative go/no-go task were retrained at 45 days of age.

A more general issue is how information acquired at one age may be expressed in performance at a later age. In this connection, young rabbits that acquire a particular CR are reported to show a topographically different CR, more appropriate to their developmental status, when presented with the CS at a later age (Rosenblatt, 1971). It would be of interest to determine for other learning processes (e.g., stimulus generalization) whether subjects receiving a delayed test would perform in accordance with the developmental period in which learning was established or the stage in which testing is administered.

\section{REFERENCE NOTES}

1. Hinderliter, C. F., \& Riccio, D. C. Age differences in response topography associated with footshock in rats. Paper presented at the meeting of the International Society for Developmental Psychobiology, New York, 1975.

2. Hinderliter, C. F., \& Riccio, D. C. Species-specific defense reactions: $A$ developmental comparison in rats. Paper presented at the annual meeting of the Eastern Psychological Association, Boston, 1977.

\section{REFERENCES}

Altman, J., \& DAs, G. D. Autoradiographic and histological evidence of postnatal hippocampal neurogenesis in rats. Journal of Comparative Neurology, 1965, 124, 319-336.

Blozovski, D., \& Cudennec, A. Passive avoidance learning in the young rat. Developmental Psychobiology, 1980, 13, 513-518.

Bolles, R. C. Species-specific defense reactions and avoidance learning. Psychological Review, 1970, 77, 620-629.

Bronstein, P. M., \& Hirsch, S. M. Ontogeny of defensive reactions in Norway rats. Journal of Comparative and Physiological Psychology, 1976, 90, 620-629.

Brunner, R. L. Age differences in one-trial passive avoidance. Psychonomic Science, 1969, 14, 134.

Campbell, B. A., \& Spear, N. E. Ontogeny of memory. Psychological Review, 1972, 79, 215-236.

Collier, A. C., \& Bolles, R. C. The ontogenesis of defensive reactions to shock in pre-weanling rats. Developmental Psychobiology, 1980, 13, 141-150.

Collier, A. C., \& MAst, J. Alleviation of avoidance deficits by approach alternatives in 10-day old pups. Physiology \& Behavior, 1979, 23, 615-618.

Jensen, R. A., \& Davis, J. L. Inhibitory avoidance learning in young rats effected by previous familiarization with the apparatus. Bulletin of the Psychonomic Society, 1978, 11, 247-248.

Livesey, D. J., \& DAwson, R. G. A learning-performance distinction during development. Behavioral Biology, 1977, 20, 25-31.

Mattingly, B. A., \& Zolman, J. F. Ontogeny of passive avoidance learning in domestic chicks: Punishment of key-peck and running responses. Journal of Comparative and Physiological Psychology, 1980, 94, 718-733.

MCAlliste R, W. R., \& MCAllister, D. E. Behavioral measurement of conditioned fear. In F. R. Brush (Ed.), Aversive conditioning and learning. New York: Academic Press, 1971.

MCCleARY, R. A. Response-modulating functions of the limbic system: Initiation and suppression. In E. Stellar \& J. M. Sprague (Eds.), Progress in physiological psychology (Vol. 1). New York: Academic Press, 1966.

RAY, D., \& NAGY, Z. M. Emerging cholinergic mechanisms and ontogeny of response inhibition in the mouse. Journal of Comparative and Physiological Psychology, 1978, 92, 335-349.

Riccio, D. C., \& Haroutunian, V. Failure to learn in a taste aversion paradigm: Associative or performance deficit? Bulletin of the Psychonomic Society, 1977, 10, 219-222.

Riccio, D. C., \& Haroutunian, V. Some approaches to the alleviation of ontogenetic memory loss. In B. A. Campbell \& N. E. Spear (Eds.), Ontogeny of learning and memory. Hillsdale, N.J: Erlbaum, 1979.

Riccio, D. C., Rohrbaugh, M., \& Hodges, L. A. Developmental aspects of passive and active avoidance learning in rats. Developmental Psychobiology, 1968, 1, 108-111.

RosenblatT, J. S. Suckling and home orientation in the kitten: A comparative developmental study. In E. Tobach, L. R. Aronson, \& E. Shaw (Eds.), The biopsychology of development. New York: Academic Press, 1971.

Schulenburg, C. J., Riccio, D. C., \& Stikes, E. R. Acquisition and retention of a passive avoidance response as a function of age in rats. Journal of Comparative and Physiological Psychology, 1971, 74, 75-83. 
Smith, G. J., \& Spear, N. E. Home environment effects on withholding behaviors and conditioning in infant and neonatal rats. Science, 1978, 202, 327-329.

Spear, N. E., \& Parsons, P. Analysis of reactivation treatment: Ontogenetic determinants of alleviated forgetting. In D. L. Medin, W. A. Roberts, \& R. T. Davis (Eds.), Processes of animal memory. Hillsdale, N.J: Erlbaum, 1976.
Stehouwer, D. J., \& Campbell, B. A. Ontogeny of passive avoidance: Role of task demands and development of speciestypical behaviors. Developmental Psychobiology, 1980, 13, 385-398.

(Received for publication August 4, 1981.) 